Research report

\title{
Long-term effects of psychotherapy on moderate depression: A comparative study of narrative therapy and cognitive-behavioral therapy
}

\author{
Rodrigo T. Lopes ${ }^{\text {a }}$, Miguel M. Gonçalves ${ }^{\mathrm{a}, *}$, Daniel B. Fassnacht ${ }^{\mathrm{b}}$, \\ Paulo P.P. Machado ${ }^{a}$, Inês Sousa ${ }^{\mathrm{c}}$ \\ a School of Psychology, University of Minho, 4710-057 Braga, Portugal \\ ${ }^{\mathrm{b}}$ Department of Psychology, James Cook University, Singapore \\ ${ }^{\mathrm{c}}$ Department of Mathematics and Applications, University of Minho, Portugal
}

\section{A R T I C L E I N F O}

Article history:

Received 25 October 2013

Received in revised form

23 May 2014

Accepted 24 May 2014

Available online 2 June 2014

Keywords:

Unipolar depression

Psychological treatment of depression

Long-term effects of psychological

treatment

Empirically supported therapies (ESTs)

Narrative therapy

Cognitive-behavioral therapy

\begin{abstract}
A B S T R A C T
Background: In a previous clinical controlled trial (Lopes et al., 2014), narrative therapy (NT) showed promising results in ameliorating depressive symptoms with comparable outcomes to cognitivebehavioral therapy (CBT) when patients completed treatment. This paper aims to assess depressive symptoms and interpersonal problems in this clinical sample at follow-up.

Methods: Using the Beck Depression Inventory-II and Outcome Questionnaire-45.2 Interpersonal Relations Scale, naturalistic prospective follow-up assessment was conducted at 21 and 31 months after the last treatment session.

Results: At follow-up, patients kept improving in terms of depressive symptoms and interpersonal problems. The odds that a patient maintained recovery from depressive symptoms at follow-up were five times higher than the odds that a patient maintained recovery from interpersonal problems. In the same way, the odds of a patient never recovering from interpersonal problems were five times higher than the odds of never recovering from depressive symptoms.

Limitations: The study did not control for the natural course of depression or treatment continuation. Conclusions: For depressed patients with greater interpersonal disabilities, longer treatment plans and alternative continuation treatments should be considered.
\end{abstract}

(c) 2014 Elsevier B.V. All rights reserved.

\section{Introduction}

The short-term effects of brief outpatient psychotherapy for unipolar depression have been widely reported in the psychotherapy research literature over the past 60 years (e.g., Cuijpers et al., 2008a; Demaat et al., 2007; Dobson, 1989; Elkin et al., 1989; Gloaguen et al., 1998; Hansen et al., 2002; Hollon and Ponniah, 2010; Lambert and Ogles, 2004). Cognitive-behavioral therapy (CBT) for depression and its variants have also been well explored (Beck et al., 1979; Butler et al., 2006; Cuijpers et al., 2008a, 2008b; Gibbons et al., 2010). Despite effective treatments, approximately $20 \%$ of patients (Keller and Boland, 1998) or more (Barkow et al., 2003; Barnhofer et al., 2013) develop a chronic form of the disorder for at least two years. Accordingly, Angst (1992) found that $75 \%$ of patients had one or more recurrences of depression at a 10 -year follow-up. The chances of having another depressive episode are approximately 50\% higher for those who have

\footnotetext{
* Corresponding author.

E-mail address: mgoncalves@psi.uminho.pt (M.M. Gonçalves).
}

already had a first major depressive episode (Hollon et al., 2002; Judd et al., 1998). The more episodes one has experienced, the more likely a patient is to experience reoccurrence or relapse. For instance, chances for a fourth episode can reach $90 \%$ for those who have already experienced three previous episodes (American Psychiatric Association, 2000). Given the recurrence and chronicity of MDD, long-term follow-ups should be considered to evaluate treatment efficacy (Chambless and Hollon, 1998; Cooper, 2008; Lambert and Ogles, 2004; Shapiro et al., 1995).

In a comparative short-term controlled clinical trial, Lopes et al. (2014) found that depressed patients who received narrative therapy (NT) showed significant reductions in depressive symptoms. The authors concluded that those who completed NT or CBT had significantly superior outcomes when compared to a waiting list benchmark (Minami et al., 2007). The dropout rate was high (approx. 35\%), which led to less impressive results on the intend-to-treat analysis compared with those who completed the treatment. A significant difference was found in depressive symptom reduction, which favored CBT when all patients, dropouts and completers, were included in the analysis. Despite this difference, no differences between treatments 
were found for interpersonal problems. Although almost half of all patients fulfilled the criteria for clinical recovery by the end of treatment (Jacobson and Truax, 1991), the rest remained unimproved. The aim of this paper is to assess long-term outcomes of the patient sample who have undergone either NT or CBT in the Lopes et al. (2014) clinical trial, with special emphasis on the differential course of depressive symptoms and interpersonal problems.

\subsection{Long-term assessment of psychotherapy outcomes}

There is vast evidence showing that psychotherapy relapse rates for depression (mainly with CBT) are significantly lower than pharmacotherapy relapse rates (e.g., 56\% against 26.5\%, Demaat et al., 2007; 60\% against 29.5\%, Gloaguen et al., 1998; 50\% against $33 \%$, Shea et al., 1992). However, there is a lack of evidence comparing the differential long-term effects of different psychological interventions (Cuijpers et al., 2008a). Although available research suggests that different psychological treatments have equivalent effects over time (Blay et al., 2002; e.g., Deffenbacher et al., 1995; Shea et al., 1992), some evidence suggests the superiority of certain treatments (Ellison et al., 2009). For instance, Shapiro et al. (1995) found equivalent post-treatment outcomes for depression through CBT and psychodynamic-interpersonal psychotherapy, but at the one year follow-up assessments, CBT showed significantly better outcomes. Given these inconsistent findings, outcome follow-up assessments seem to be an essential part of studies on the effectiveness of psychological treatments (Chambless and Hollon, 1998; Cooper, 2008; Lambert and Ogles, 2004).

Evidence suggests that post-treatment scores predict follow-up scores (Cooper, 2008; Nicholson and Berman, 1983; Robinson et al., 1990), and some studies suggest a delayed response to treatment. For instance, Anderson and Lambert (2001) found that among 102 patients, who were treated for diverse psychological problems, the overall improvement rate increased from 39\% at post-treatment to $53 \%$ at the six-month follow-up. Keller et al. (1992) also showed that the probability of depression recovery was $70 \%$ two years after discharge and increased up to $80 \%$ three years after discharge. Accordingly, in research studying longer follow-up periods, recovery rates increased from $20.4 \%$ at 15 years after discharge to $32.7 \%$ at 25 years after discharge (Brodaty et al., 2001). Clinical gains are thus expected in the follow-up assessments.

Despite findings that suggest some post-treatment improvement, limited follow-up intervals are major limitations in most long-term effect studies of psychotherapy; patients are often assessed for no longer than a year after treatment (Cooper, 2008; Westen and Morrison, 2001). This trend of relatively short follow-ups appears in a systematic review of 53 high-quality comparative outcome studies examining psychotherapy for depression (Cuijpers et al., 2008a). This study revealed a mean follow-up period of 5.6 months ( $S D=5.1$, median=four months), and $93.4 \%$ of the studies only reported follow-up data for less than 12 months (only one study presented 24-month follow-up data). To the authors' knowledge, the only study that evaluated the follow-up effects of NT for depression (Vromans and Schweitzer; 2011) had a brief follow-up interval (of only three months). Therefore, to better understand the long-term effects of psychological treatment, a longer follow-up period (more than one year) is strongly recommended (Brodaty et al., 2001; Cooper, 2008; Lambert and Ogles, 2004; Lambert, 2007).

\subsection{Symptomatic vs. interpersonal change in depression}

In daily practice, clinicians frequently observe that symptomatic change occurs faster than changes on interpersonal levels (e.g., interpersonal problems, dysfunctional relationship patterns). Accordingly, the phase model of change (Howard et al., 1993; Swift et al., 2010) suggests that interpersonal improvements will take longer to achieve when compared to symptomatic improvements. Research examining brief treatments supports this observation. For instance, Kopta et al. (1994) assessed clinically significant changes for different symptom clusters. The authors found that for $50 \%$ of patients to recover from symptoms of acute distress, five sessions were necessary. For the same $50 \%$ of patients to recover from chronic distress, 14 sessions were necessary. For the characterological symptoms cluster, which described interpersonal problems, more than 104 sessions were required for $50 \%$ of patients to recover, suggesting greater constancy of these problems. In another study, Barkham et al. (2002) assessed 105 moderately depressed patients who were assigned to three treatment conditions with different therapy lengths, i.e., two-session, eight-session and 16-session intervention conditions. Results revealed that although many patients recovered from depressive symptoms, significantly fewer patients recovered from interpersonal problems in all conditions. Accordingly, a reanalysis of the data from the Lopes et al. (2014) clinical trial found that more patients have improved depressive symptoms than improved interpersonal problems and that depressive symptom improvement occurred significantly faster than interpersonal problem improvement during their brief psychological treatment of depression (Lopes et al., 2013). This finding suggests that time might be an important factor in improving interpersonal problems.

None of the aforementioned studies showed evidence of the long-term differential effects of different psychotherapies on depressive symptoms and interpersonal problems (i.e., the phase model). Thus, it is our goal to evaluate whether the differential recovery from depressive symptoms and interpersonal problems is maintained or reduced in a long-term evaluation and whether these changes are different in CBT when compared to NT.

\subsection{Research questions}

The general purpose of this study is to evaluate the long-term effects of NT and CBT in the aforementioned clinical trial (Lopes et al., 2014) and to assess whether the two treatments differ in stability over time. To address the aforementioned evidence gap, specific research questions include the following: (1) Are therapeutic gains maintained over time at 21- and 31-month followups, i.e., do patients keep improving, stabilize or relapse? (2) Do changes in depressive symptoms differ from changes in interpersonal problems at long-term follow-ups? (3) Do any of these effects (referred to in Questions 1 and 2) have differential outcomes according to treatment modality (i.e., NT and CBT)?

\section{Method}

\subsection{Participants}

The sample in the original study (Lopes et al., 2014) comprised 63 patients diagnosed with major depressive disorder (MDD; American Psychiatric Association, 2000) with moderate severity at the onset of the study [Global Assessment of Functioning (GAF, American Psychiatric Association, 2000): $M=59.84(S D=10.47)]$. Some patients (20.6\%) were included in the sample with secondary anxiety diagnoses or symptoms. Two patients (3\%) had pretreatment scores in the functional range of the BDI-II, and seven patients (11\%) had scores in the functional range of the OQ-45.2 IR subscale (Lopes et al., 2013). Patients were blindly assigned according to their incoming order, alternating between NT $(n=34)$ and CBT $(n=29)$. All baseline demographic and clinical characteristics were equivalent for both groups. Patients were on average 35.44 years old $(S D=11.51)$, and $81 \%$ were female. 
NT patients received on average 12.94 sessions $(S D=7.05)$, and CBT patients received on average 14.90 sessions $(S D=6.48)$; $t(61)=-1.13, p=.26$ (this figure includes the dropouts).

Ten therapists participated in the study, along with two experienced supervisors (one in NT and one in CBT). Mostly female (70\%), the therapists had on average 1.9 years of clinical experience $(S D=2.13)$ and were on average 26 years old $(S D=4.2)$. They were all psychologists and graduate students in the Clinical Psychology Program (six at the master's level and four at the Ph.D. level). In Portugal, psychologists complete a five-year program (master's degree), including a one-year clinical internship, which is the minimum training required for supervised practice. Reported years of experience do not include this internship. The therapists also received specific training on the relevant treatment manual (for more information, see Lopes et al., 2014).

\subsection{Treatment conditions}

The CBT group followed the CBT treatment manual for depression, which is well described in the literature (Beck et al., 1979; Leahy and Holland, 2000; Rush et al., 1977). The NT treatment manual (Gonçalves and Bento, 2008) was developed specifically for the clinical trial and is based on the work of Michael White (White and Epston, 1990; White, 2007). In both conditions, treatment was planned to be 20-60-minute sessions. Sessions 116 were scheduled weekly, whereas sessions 17-20 were scheduled every other week. Overall, patients received on average 13.9 sessions $(S D=6.8)$, and the median was 16 sessions (Lopes et al., 2013). Some patients terminated earlier, either agreeing with the therapist that therapy goals had been achieved or through a unilateral decision by the patient (dropout). Adherence to the manual and therapist competence were monitored through weekly supervisions (using session videotapes) and were assessed from external judges' perspectives using a scale developed for this purpose (Adherence and Competence Scale for Narrative and Cognitive-Behavioral Therapy [ACS-N-CBT]; Gonçalves et al., 2009), showing good results (Lopes et al., 2014).

Patient and therapist characteristics, therapist training, the two treatment manuals and adherence and competence assessments are described in detail in the original trial report (Lopes et al., 2014).

\subsection{Measures}

\subsubsection{Beck depression inventory-II}

The BDI-II (Beck et al., 1996) was used to measure depressive symptoms, with a scale ranging from 0 (absence of depressive symptoms) to 63 (severe depressive symptoms). It is considered the gold standard for self-report measures that assess depression for research purposes (Hatfield and Ogles, 2004). The BDI-II has shown a high internal consistency $(\alpha=.89$ in the present ITT sample and $\alpha=.91$ in Steer et al., 2001). The measure has been translated to and validated for Portuguese populations (Campos and Gonçalves, 2011; Coelho et al., 2002). Because the Portuguese studies did not calculate the reliable change index (RCI; Jacobson and Truax, 1991), normative data gathered from a meta-analysis of diverse samples (Seggar et al., 2002) were used to calculate the proportion of clinical change $(\mathrm{RCI}$, for improvement $=8.46$; cut-off score $=14.29$ ).

\subsubsection{Outcome questionnaire- 45.2}

The OQ-45.2 (Lambert et al., 1996a, 1996b) is a self-report questionnaire designed to assess patients' progress throughout therapy and its termination. It assesses not only psychological distress but also interpersonal relations and the social role of the patient. It comprises 45 self-report items rated on a five-point scale (ranging from 0 to 4 ). The Cronbach's alpha was 93 in various clinical samples (De Jong et al., 2007; Lambert et al., 1996a), and similar reliability was obtained in our sample $(\alpha=.89)$, which indicates excellent internal consistency. The current analysis used the 11 self-report items of the interpersonal relations subscale (OQ.45-IR, Lambert et al., 1996b), which aims to assess interpersonal complaints (e.g., loneliness, conflicts with others, family and marriage problems and sexual concerns). This scale provides a total score between 0 and 44, with higher scores indicating interpersonal problems (Lambert et al., 1996b). Lambert et al. (1996a) found good internal consistency $(\alpha=.74)$ and test-retest reliability $(r=.80)$. Umphress et al. (1997) reported good concurrent validity for the OQ-45.2 IR subscale. High correlations were found between the OQ-45.2 IR and the Inventory of Interpersonal Problems (IIP; Horowitz et al., 2000, 1988), a widely used measure of interpersonal functioning. The RCI and the clinical cut-off score (Jacobson and Truax, 1991) for the OQ-45.2 IR were calculated for the Portuguese population (Machado and Fassnacht, 2014). Change is considered reliable when a patient's score changes by at least eight points, and scores above 14 points are considered dysfunctional.

\subsection{Procedures}

All patients who took part in the clinical trial (Lopes et al., 2014) were contacted for follow-ups no matter how many therapy sessions they received or how treatment was terminated. The type of termination was either a consentaneous decision between therapist and patient (completers) or a unilateral decision by the patient (dropouts). All patients were contacted by telephone. The first follow-up occurred an average of 21.3 months $(S D=7)$ after therapy ended, and the second follow-up occurred an average of 31.3 months $(S D=9.1)$ after therapy ended. Phone calls were made every two days at different times of the day for approximately one month until the researcher had reached the patient. Patients' research availabilities and questionnaire preferences (i.e., responding electronically, by post, or with a researcher's assistance) were checked by phone. Those who were not reached by phone had the invitation to participate and have the questionnaires sent via e-mail or post.

\subsection{Analysis}

Chi-square analyses were used to determine whether return rates (i.e., the percentage of questionnaires sent out that were returned) differed by condition, therapy completion or treatment response. Independent $t$-tests were used to assess pre-treatment differences among conditions.

\subsubsection{Analysis of continuous data}

Random intercepts, random slopes, mixed growth curve models using time as a continuous variable (months after treatment termination) and treatment condition as a between-subjects factor were fitted to compare depressive symptoms and interpersonal problems across the two treatment conditions (NT to CBT) over time. All models were fitted using restricted maximum likelihood.

\subsubsection{Clinical significance analysis}

Individual responses for both treatment conditions at 21- and 31-month follow-up observations were assessed with the maintenance of recovery, relapse at follow-up, recovery at follow-up and maintenance of symptoms categories using Jacobson and Truax's (1991) criteria, the most widely used method of assessing clinically significant change in psychotherapy research (Bauer et al., 2004; Kendall et al., 2004; Ogles et al., 2001). Maintenance of recovery 
was assigned when a patient's follow-up scores remained below the clinical cut-off in the range typical for a functional population (i.e., 14.29 for BDI-II and 14 for OQ-45.2 IR). Relapse at follow-up was assigned to patients who had recovered (i.e., attained clinical significant change) at termination and scored higher than the clinical cut-off (i.e., in the range typical for a dysfunctional population range) at follow-up assessments. Recovery at follow-up was assigned to patients who had not recovered at post-treatment but had recovered at follow-up assessments. Maintenance of symptoms was assigned to patients who had not recovered at posttreatment neither at follow-up. Fisher's exact tests were used to determine the between-group association of the clinical categories providing two-tailed $p$-values (Preacher and Briggs, 2001).

\subsubsection{Effect sizes}

Effect sizes were expressed in odds ratios, which are widely used in medical reports to "provide an estimate (with confidence interval) for the relationship between two binary variables" (Bland and Altman, 2000, p. 1468). They are used as common indices to compare recovery and relapse in the depressive symptom and interpersonal problem domains.

\section{Results}

Fig. 1 describes the flow of participants in the clinical trial: at the 21-month follow-up observation, 35 patients were assessed (10 were dropouts and 25 were completers); at the 31-month follow-up observation, 42 patients were assessed ( 13 dropouts and 29 completers). Twenty-eight patients at the 21-month follow-up and 21 patients at the 31-month follow-up were not reached by the staff by any means. The time elapsed between treatment termination and follow-up assessment did not differ between treatment groups [21 months: $t(33)=1.34, p=.189 ; 31$ months: $t$ $(40)=1.43, p=.160]$. The reasons for attrition at follow-up were as follows: participants did not reply ( $n=11$ at 21 months and $n=5$ at the 31 months) or had moved away and/or changed their phone numbers ( $n=4$ at 21 months and at 31 months).

One "major problem with follow-up designs is that they are particularly susceptible to bias resulting from differential retention" (Chambless and Hollon, 1998, p. 10). To ensure that the present follow-up samples were comparable with the initial RCT sample, possible bias due to differential retention was assessed.

\subsection{Differential attrition}

Overall return rates of 55.5\% at the 21-month follow-up and $66.6 \%$ at the 31-month follow-up were achieved. A Pearson's chisquare test revealed no return rate differences between the two treatment conditions [59.9\% for NT and 58.6\% for CBT at 21 months, $\chi^{2}(1, N=63)=.20, p=.651$; and $64.7 \%$ for NT and $69 \%$ for CBT at 31 months, $\left.\chi^{2}(1, N=63)=.13, p=.721\right]$. There was also no differential attrition according to recovery status; at 21 and 31 months, return rates for recovered patients were $63.6 \%$ and $81.8 \%$, respectively, and for non-recovered patients, $51.2 \%$ and $58.5 \%$, respectively [21-month follow-up: $\chi^{2}(1, N=63)=.89, p=.344 ; 31$ month follow-up: $\chi^{2}(1, N=63)=3.49, p=.062$ ]. Return rates were not higher among treatment completers when compared with dropouts [21-month follow-up: $62.5 \%$ completers vs. $43.5 \%$ dropouts, $\chi^{2}(1, \quad N=63)=2.14, \quad p=.144 ; 31$-month follow-up: $72.5 \%$ completers $v s .56 .5 \%$ dropouts, $\left.\chi^{2}(1, N=63)=1.68, p=.195\right]$. In summary, these findings suggest that the retained follow-up samples were not biased by differential return according to treatment condition, therapy completion or treatment response.

\subsection{Pre-treatment differences between NT and CBT}

Although the two treatment groups did not show pre-treatment differences in the original study (Lopes et al., 2013, 2014), the present retained sample was re-analyzed to ensure that long-term findings at follow-up would not be inadvertently confounded by pre-treatment differences among conditions. Table 1 shows means and standard deviation values for both measures at all time-points. Independent $t$ tests revealed no significant pre-treatment differences across conditions based on initial severity [BDI-II: $t(32)=-1.942, p=.061$; OQ45.2 IR: $t(32)=-1.027, p=.312$ ], which supports the idea that this sample is not obviously biased by pre-treatment differences.

\subsection{Course of symptoms at follow-up and differences across treatments}

\subsubsection{Analysis of continuous data}

Using time as a continuous variable (months since treatment termination) and treatment condition as a between-subjects factor, the random intercepts, fixed slopes ${ }^{1}$ mixed growth curve model revealed a main effect of time on the BDI-II $[F(1,89.82)=$ $13.83, p<.001]$ but no interaction effect of time and treatment $[F(1,89.82)=.71, p=.402]$. Thus, patients on average continued reducing depressive symptoms at follow-ups, no matter their treatment. An equivalent result was found on the OQ-54.2 IR. There was a main effect of time $[F(1,92.76)=7.88, p=.006]$ but no interaction effect of time and treatment $[F(1,92,76)=.42, p=.521]$, which indicated that patients on average continued reducing interpersonal problems at follow-up observations, no matter their treatment.

\subsubsection{Clinical significance}

Patients' follow-up scores were examined to determine whether the patient (a) maintained recovery at follow-up, (b) relapsed at follow-up, (c) recovered at follow-up or (d) remained dysfunctional at follow-up.

3.3.2.1. Course of depressive symptoms at follow-up. The course of depressive symptoms (measured by BDI-II) from termination to follow-ups is presented in Table 2.

In the NT condition, 22\% $(n=4 / 18)$ of patients maintained therapy gains at 21 months and $27 \%(n=6 / 22)$ at 31 months after therapy termination. In the CBT condition, $41 \%(n=7 / 17)$ of patients maintained therapy gains at 21 months and $30 \%(n=6 /$ 20) at 31 months after therapy termination. Comparing the two conditions, no significant differences were found (Fisher's exact test: 21 months, $p=.29$; 31 months, n.s.).

A small proportion of patients experienced relapses at the 21month follow-up [NT=6\% (1/18) and CBT =12\% $(2 / 17), p=.60]$ and at the 31-month follow-up [NT=5\% (1/22) and $\mathrm{CBT}=25 \%(5 / 20)]$. A substantial number of patients also remained depressed at the 21month $[\mathrm{NT}=39 \%(7 / 18)$ and $\mathrm{CBT}=18 \%(3 / 17), p=.26]$ and 31-month follow-up assessments [NT $=41 \%(9 / 22)$ and $\mathrm{CBT}=20 \%(4 / 20), p=.19]$.

An interesting finding is that $33 \%(6 / 18)$ of NT patients and $29 \%$ (5/17) of CBT patients had not improved at post-treatment but did recover after 21 months (i.e., $31 \%$ of the total sample). However, no differences were found between the two treatment conditions (n.s.). At the 31-month follow-up, this proportion of patients was maintained: $27 \%$ of the NT patients (6/22) and $25 \%$ of the CBT patients (5/ 20) who had not recovered during treatment had recovered 31 months after treatment termination (i.e., 26\%, of the total sample).

\footnotetext{
${ }^{1}$ For both the BDI-II and the OQ-45.2 IR, random intercepts, fixed slopes mixed growth curve models were fitted. However, the random slopes did not account for any significant variance in the models and are not reported here.
} 


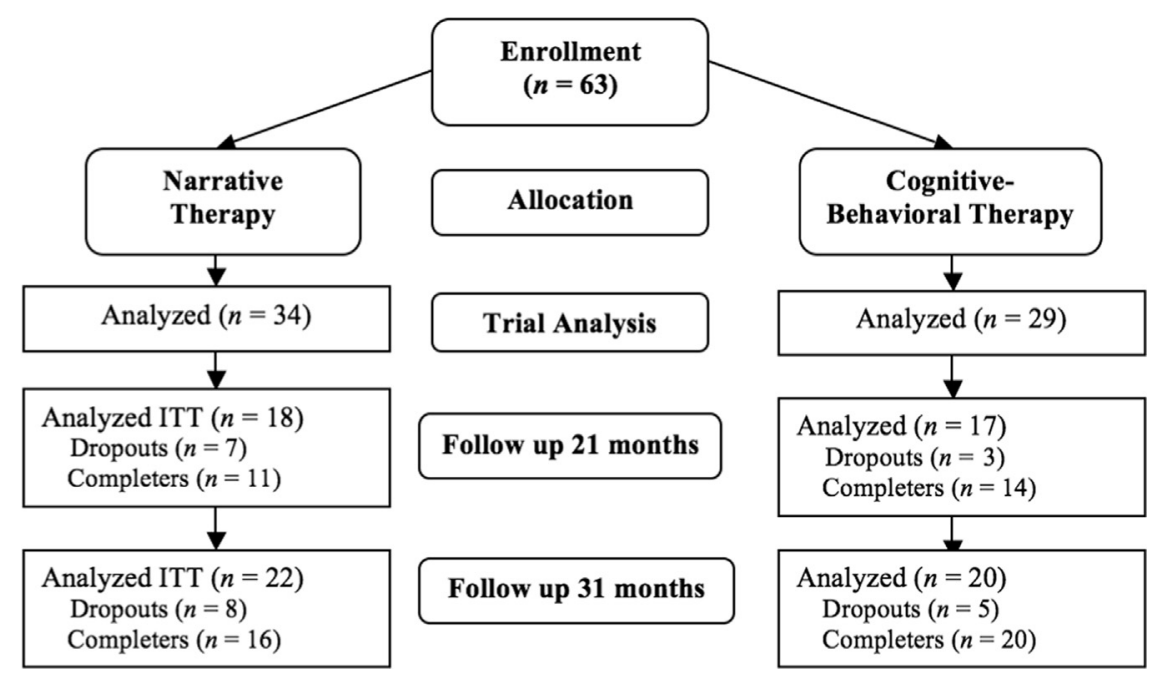

Fig. 1. Flow diagram for the Lopes et al. (2014) clinical trial and follow-up assessments.

Table 1

Means and standard deviations at pre-, post-treatment, 21- and 31-months follow-up observations, by treatment conditions.

\begin{tabular}{|c|c|c|c|c|c|c|}
\hline & \multicolumn{2}{|c|}{ Cognitive-behavioral therapy } & \multicolumn{2}{|c|}{ Narrative therapy } & \multicolumn{2}{|l|}{ Whole sample } \\
\hline & $M(S D)$ & $n$ & $M(S D)$ & $n$ & $M(S D)$ & $N$ \\
\hline \multicolumn{7}{|l|}{ BDI-II } \\
\hline Pre-treatment & $33.90(11.47)$ & 229 & 29.09 (9.63) & 335 & $31.30(10.70)$ & 663 \\
\hline Post-treatment & $18.90(13.34)$ & 229 & 22.59 (13.19) & 335 & $20.89(13.28)$ & 663 \\
\hline 21-Months follow-up & $9.88(7.83)$ & 117 & $12.89(10.09)$ & 118 & $11.43(9.06)$ & 335 \\
\hline 31-Months follow-up & $13.45(10.86)$ & 220 & $13.50(10.84)$ & 222 & $13.48(10.71)$ & 442 \\
\hline \multicolumn{7}{|l|}{ OQ-45.2 IR } \\
\hline Pre-treatment & $21.41(5.79)$ & 29 & $20.71(5.76)$ & 335 & $21.03(5.74)$ & 663 \\
\hline Post-treatment & $18.07(7.58)$ & 229 & $19.15(7.74)$ & 335 & $18.65(7.63)$ & 663 \\
\hline 21-Months follow-up & $13.00(7.52)$ & 117 & 16.94 (6.69) & 118 & $15.03(7.28)$ & 335 \\
\hline 31-Months follow-up & $13.80(6.96)$ & 220 & $15.86(6.08)$ & 222 & $14.88(6.52)$ & 442 \\
\hline
\end{tabular}

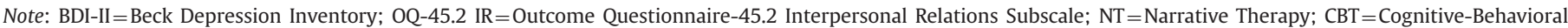
Therapy. Pre- and post-treatment scores are also reported at Lopes et al. (2014).

3.3.2.2. Course of interpersonal problems at follow-up. The course of interpersonal problems (measured by the OQ-45.2 IR) from termination to follow-ups is presented in Table 2. Again, no differences were found between the two treatment conditions.

A small proportion of patients $(11 \% ; 4 / 35)$ had recovered from interpersonal problems at post-treatment and maintained recovery at the 21 -month follow-up [NT $=5.5 \%(1 / 18)$; $\mathrm{CBT}=18 \%$ (3/17), $p=.33$ ]. At the 31-month follow-up, similar proportions of patients $(7 \% ; 3 / 17)$ remained recovered $[\mathrm{NT}=9 \%(2 / 22) ; \mathrm{CBT}=5 \%$ $(1 / 20)$, n.s.]. Only a small proportion of patients $(9 \% ; 3 / 35)$ who had recovered at post-treatment relapsed at the 21-month followup $[\mathrm{NT}=11 \% \quad(2 / 18) ; \quad \mathrm{CBT}=6 \% \quad(1 / 17), \quad$ n.s. $], \quad$ whereas $18 \%$ (4/42) experienced a relapse at the 31-month follow-up [NT $=9 \%$ $(2 / 22)$; $\mathrm{CBT}=10 \%(2 / 20), p=1]$. On the other hand, a large proportion of patients [21 months: NT=78\% (14/18); CBT=53\% (9/17), $p=.16$; and 31 months: $\mathrm{NT}=73 \%(16 / 22) ; \mathrm{CBT}=60 \%(12 / 20)$, $p=.52]$ were still considered interpersonally dysfunctional at the follow-up.

\subsection{Comparison of depressive symptoms and interpersonal problems at follow-up}

To compare recovery and relapse rates for depressive symptoms and interpersonal problems (Question 2), odds ratios between recovery and relapse rates are reported (Table 3).
A small proportion of patients recovered from interpersonal problems at post-treatment and maintained recovery at follow-up [21 months $=11 \%(4 / 35) ; 31$ months $=7 \%$ (3/42)]. Comparing this finding to the proportion of patients who maintained recovery from depressive symptoms at follow-up, significant odds ratios were obtained at both follow-up observations [21 months: BDI$\mathrm{II}=31 \%(11 / 35)$, OQ-45.2 IR=11\% (4/35); odds ratio $=3.55, z=1.97$, $p=.049 ; 31$ months: $\mathrm{BDI}-\mathrm{II}=29 \%(12 / 42)$; OQ-45.2 IR=7\% (3/42); odds ratio $=5.20, z=2.391, p=.016]$. Thus, at the 21-month followup, patients who had recovered at post-treatment were 3.55 times more likely to maintain recovery from depressive symptoms than from interpersonal problems; likewise, at the 31-month follow-up, patients who had recovered at post-treatment were 5.20 times more likely to maintain recovery from depressive symptoms than from interpersonal problems.

Another significant finding is the high proportion of patients who had not recovered during treatment and remained dysfunctional in terms of interpersonal problems [21 months $=66 \%(23 /$ 35); 31 months $=66 \%$ (28/42)]. Comparing this finding with the proportion of patients who had not recovered during treatment and remained dysfunctional in terms of depressive symptoms [21 months: 29\% (10/35); 31 months=31\% (13/42)], significant odds ratios were obtained at both follow-up observations. Hence, at both follow-up observations, patients who had not recovered were approximately five times more likely to remain dysfunctional in 
Table 2

Proportion of patients remaining well or relapsing over 21 and 31 months follow-up assessments, by treatment group.

\begin{tabular}{|c|c|c|c|c|c|c|}
\hline & \multicolumn{2}{|c|}{21 Months Follow-up $(N=35)$} & \multirow{2}{*}{$\begin{array}{l}\text { Fisher's exact } \\
\text { probability }\end{array}$} & \multicolumn{2}{|c|}{31 Months Follow-up $(N=42)$} & \multirow{2}{*}{$\begin{array}{l}\text { Fisher's exact } \\
\text { probability }\end{array}$} \\
\hline & $\begin{array}{l}\text { NT } \\
(n=18)\end{array}$ & $\begin{array}{l}\text { CBT } \\
(n=17)\end{array}$ & & $\begin{array}{l}\text { NT } \\
(n=22)\end{array}$ & $\begin{array}{l}\mathrm{CBT}(n=20) \\
(n=20)\end{array}$ & \\
\hline \multicolumn{7}{|l|}{ Depressive symptoms (according to BDI-II) } \\
\hline Recovered $^{\mathrm{a}}$ after treatment and & 4 & 7 & & 6 & 6 & \\
\hline maintained $^{\mathrm{b}}$ at follow-up & $22 \%$ & $41 \%$ & .29 & $27 \%$ & $30 \%$ & n.s. \\
\hline Recovered after treatment and & 1 & 2 & & 1 & 5 & \\
\hline relapsed ${ }^{\mathrm{C}}$ at follow-up & $6 \%$ & $12 \%$ & .60 & $5 \%$ & $25 \%$ & .09 \\
\hline Not recovered after treatment and & 6 & 5 & & 6 & 5 & \\
\hline recovered at follow-up & $33 \%$ & $29 \%$ & n.s. & $27 \%$ & $25 \%$ & n.s. \\
\hline Not recover after treatment and & 7 & 3 & & 9 & 4 & \\
\hline maintained dysfunctional at follow-up & $39 \%$ & $18 \%$ & .26 & $41 \%$ & $20 \%$ & .19 \\
\hline \multicolumn{7}{|c|}{ Interpersonal problems (according to OQ-45.2 IR) } \\
\hline Recovered ${ }^{\mathrm{a}}$ after treatment and & 1 & 3 & & 2 & 1 & \\
\hline maintained $^{\mathrm{b}}$ at follow-up & $5.5 \%$ & $18 \%$ & .33 & $9 \%$ & $5 \%$ & n.s. \\
\hline Recovered after treatment and & 2 & 1 & & 2 & 2 & \\
\hline relapsed ${ }^{\mathrm{C}}$ at follow-up & $11 \%$ & $6 \%$ & n.s. & $9 \%$ & $10 \%$ & n.s. \\
\hline Not recovered after treatment and & 1 & 4 & & 2 & 5 & \\
\hline recovered at follow-up & $5.5 \%$ & $23 \%$ & .18 & $9 \%$ & $25 \%$ & .23 \\
\hline Not recover after treatment and & 14 & 9 & & 16 & 12 & \\
\hline maintained dysfunctional at follow-up & $78 \%$ & $53 \%$ & .16 & $73 \%$ & $60 \%$ & .52 \\
\hline
\end{tabular}

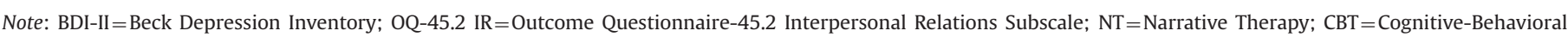
Therapy. Percentages refer to patients with follow-up data.

a Jacobson and Truax (1991)'s clinical significance criteria were used to establish whether a patient has recovered: reliable improvement (BDI-II improvement > 8.46; OQ-45.2 IR improvement $>8$ ) and decrease into the functional range (BDI-II $<14.29$; OQ-45.2 IR $<14$ ).

${ }^{\mathrm{b}}$ Maintenance of recovery: scores at follow-up assessments stayed in the functional range (BDI-II $<14.29$; OQ-45.2 IR $<14$ ).

${ }^{c}$ Relapse: scores at follow-up assessments increased into the dysfunctional range (BDI-II $>14.29$, OQ-45.2 IR $>14$ ).

Table 3

Comparison of the proportion of patients remaining well or relapsing over 21 and 31 months follow-up assessments, according to BDI-II and OQ45-IR.

\begin{tabular}{|c|c|c|c|c|c|c|c|c|}
\hline & \multicolumn{4}{|c|}{21 months Follow-up $(N=35)$} & \multicolumn{4}{|c|}{31 Months follow-up $(N=42)$} \\
\hline & BDI-II & OQ-45.2 IR & Odds ratio & $95 \% \mathrm{CI}$ & BDI-II & OQ-45.2 IR & Odds Ratio & $95 \% \mathrm{CI}$ \\
\hline \multirow{2}{*}{$\begin{array}{l}\text { Recovered }{ }^{\mathrm{a}} \text { after treatment and } \\
\text { maintained }^{\mathrm{b}} \text { at follow-up }\end{array}$} & 11 & 4 & 3.55 & {$[1.00,12.55]^{*}$} & 12 & 3 & 5.20 & {$[1.34,20.09]^{*}$} \\
\hline & $31 \%$ & $11 \%$ & & & $29 \%$ & $7 \%$ & & \\
\hline \multirow{2}{*}{$\begin{array}{l}\text { Recovered after treatment and } \\
\text { relapsed }{ }^{\mathrm{C}} \text { at follow-up }\end{array}$} & 3 & 3 & 1.00 & {$[.18,5.33]$} & 6 & 4 & 1.58 & {$[.41,6.08]$} \\
\hline & $9 \%$ & $9 \%$ & & & $14 \%$ & $10 \%$ & & \\
\hline \multirow{2}{*}{$\begin{array}{l}\text { Not recovered after treatment and } \\
\text { recovered at follow-up }\end{array}$} & 11 & 5 & 2.75 & {$[.84,8.99]$ dagger; ${ }^{\dagger}$} & 11 & 7 & 1.77 & {$[.61,5.14]$} \\
\hline & $31 \%$ & $14 \%$ & & & $26 \%$ & $17 \%$ & & \\
\hline \multirow{2}{*}{$\begin{array}{l}\text { Not recover after treatment and } \\
\text { maintained dysfunctional at follow-up }\end{array}$} & 10 & 23 & .20 & {$[.08, .57]^{* * *}$} & 13 & 28 & .22 & {$[.09, .56]^{* * *}$} \\
\hline & $29 \%$ & $66 \%$ & & & $31 \%$ & $66 \%$ & & \\
\hline
\end{tabular}

Note: BDI-II=Beck Depression Inventory; OQ-45.2 IR=Outcome Questionnaire-45.2 Interpersonal Relations Subscale. Percentages refer to patients with follow-up data.

a Jacobson and Truax (1991)'s clinical significance criteria were used to establish whether a patient has recovered: reliable improvement (BDI-II improvement > 8.46; OQ-45.2 IR improvement $>8$ ) and decrease into the functional range (BDI-II $<14.29$; OQ-45.2 IR $<14$ ).

b Maintenance of recovery: scores at follow-up assessments stayed in the functional range (BDI-II $<14.29$; OQ-45.2 IR $<14$ ).

${ }^{c}$ Relapse: Scores at follow-up assessments increased into the dysfunctional range (BDI-II $>14.29 ;$ OQ-45.2 IR $<14$ ).

$* p<.05$.

*** $p<.01$.

$\dagger p<.10$.

terms of interpersonal problems when compared with depressive symptoms (21 months: odds ratio=.20, $z=3.033, p=.0002 ; 31$ months: odds ratio $=.22, z=3.199, p=.001$ ).

To summarize the comparison between the symptomatic and interpersonal domains, Fig. 2 shows the proportions of recovered patients on the BDI-II and OQ-45.2 IR at post-treatment and at the 21- and 31-month follow-ups.

\section{Discussion}

The aim of this study was to prospectively evaluate a sample of depressed patients who had previously received NT or CBT in a controlled clinical trial (Lopes et al., 2014). In all analyses, allocation to treatment group (i.e., NT or CBT) did not have significant impact on any of the variables studied. We should note that although CBT appears to perform better at the clinically significant evaluation at follow-up, these findings merely represent trends, so no inferences of CBT's superiority can be drawn from this dataset.

A case-by-case clinical significance analysis of depressive symptoms reveals that one-third of all patients maintained treatment gains at follow-up and few patients relapsed (approximately 10\%). Although almost half of the patients scored in the dysfunctional range at follow-up (by either relapsing or never recovering), around one-third of all patients did recover at follow-up. A multi-level analysis confirms this latter finding, showing that on average patients 


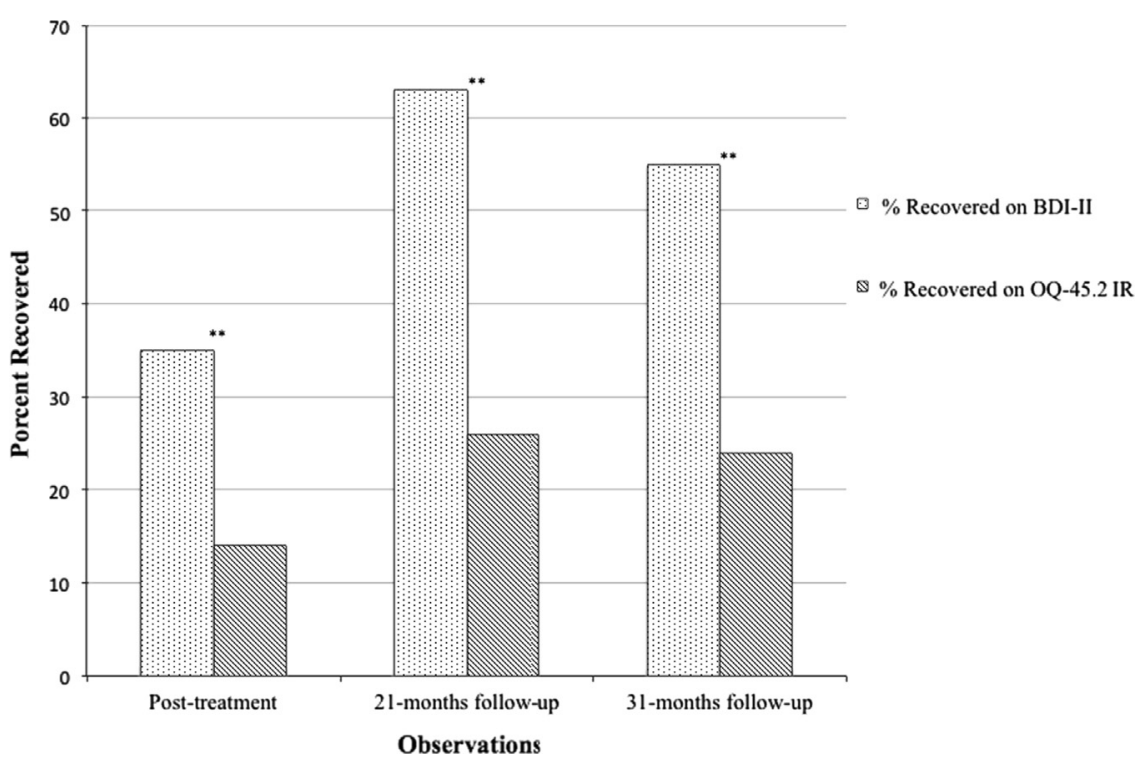

Fig. 2. Proportions of patients recovering from depressive symptoms and interpersonal problems at post-treatment and follow-ups. Note: BDI-II = Beck Depression Inventory, OQ-45.2 IR = Outcome Questionnaire-45.2 Interpersonal Relations Subscale. ${ }^{* *}$ p < .01.

continued ameliorating depressive symptoms and interpersonal problems from treatment termination through the 21 - and 31-month follow-up observations. The continuing improvement over time may corroborate the argument that psychotherapy, unlike psychopharmacological interventions, will improve actual symptoms and help patients to develop strategies to cope with the underlying mechanisms that are responsible for lasting depressive symptoms (Beck et al., 1979; Chambless and Hollon, 1998; DeRubeis et al., 2005; Hollon et al., 2005). Similarly, our study's recovery rate for depressive symptoms at follow-up (approximately one-third) was superior to that of earlier studies. For instance, Keller et al. (1992) observed a 21\% recovery rate at a 24-month follow-up.

Notably, even in a long-term evaluation, interpersonal problems still seem to be much more resistant to change than depressive symptoms. Only approximately 10\% of patients keep their interpersonal gains at follow-up, and only approximately $15 \%$ of patients who did not recover in interpersonal domain during treatment did recover by the follow-up observation. At the same time, a large proportion of patients (approximately 66\%) still reported interpersonal problems (i.e., with scores in the dysfunctional range) at follow-up. This finding is in line with the posttreatment outcomes of this very sample (Lopes et al., 2013), with the phase model (Howard et al., 1993; Swift et al., 2010) and with previous research comparing the course of depressive symptoms and interpersonal problems during and after treatment (Barkham et al., 2002, 1993, 1996; Hilsenroth et al., 2001; Kopta et al., 1994; Vromans and Schweitzer, 2011).

Unfortunately, interpersonal impairment is highly associated with depression (Hammen and Brennan, 2002; Hecht et al., 2005; McEvoy et al., 2013). Still, it was not within the scope of this study to address the relationships between the symptomatic and interpersonal domains; this study instead sought to confirm the stability of the interpersonal domain when compared with the symptomatic domain. In future research, it is crucial to better understand the possible causal relationships between interpersonal malfunctioning and depression.

\subsection{Limitations}

Although follow-up studies are an important part of psychotherapy outcome research, they are hard to conduct and difficult to interpret (Chambless and Hollon, 1998). In general, it is hard to know what interferes with patient progress in psychotherapy research; in long-term follow-up evaluations, this problem is even more salient. Keeping this limitation in mind, the results presented here are not intended to prove any cause-effect relationship between psychotherapy treatment and clinical outcomes after 21 or 31 months because the study did not control for spontaneous remission, the natural course of depression or treatment continuation during the follow-up period (e.g., medication or alternative treatments, including psychotherapy). Another confounding variable might be the chronicity of the depressive symptoms; e.g., acutely and chronically depressed patients were not analyzed separately in the present study. As Keller and Shapiro (1982) showed, outcomes for patients with chronic depression are clearly different from those who have a single acute episode. This difference could be an important issue to consider in future studies.

Another limitation of this study involves the assessment method. The available data did not allow pinpointing when the patient relapsed. Future follow-up designs should employ a more regular assessment schedule (Chambless and Hollon, 1998).

\subsection{Strengths}

As the preliminary analysis shows, the retained sample for long-term follow-up is representative of the original treatment sample. These findings are also not biased by low or differential returns (according to treatment condition, treatment completion and treatment response) or pre-treatment differences among conditions.

Another study strength is the relatively long follow-up period, which is longer than the average period observed in the literature. Moreover, the present return rates are similar to those of other reports in psychotherapy research with shorter follow-up periods (Barkham et al., 1999; Snell et al., 2001; e.g., Vromans and Schweitzer, 2011). In addition, studies rarely compare the differential long-term efficacy of psychotherapy models. Furthermore, it is recommended that "the length of the follow-up required is likely to depend on the natural course of the disorder in question and the strength and stability of the treatment effect that is worthy of detection" (Chambless and Hollon, 1998, p. 10). As a cornerstone of studies examining the natural course of depression, the Collaborative Depression Study (CDS; Katz and Klerman, 1979) found that by the second year of follow-up, $20 \%$ of patients remained ill (Keller et al., 1982). The same sample of patients was assessed three years later (a five-year follow-up), and only $12 \%$ of 
patients remained ill (Keller et al., 1992). Subsequent follow-ups at 10 (Mueller et al., 1996) and 15 years (Keller and Boland, 1998) found that $7 \%$ and $6 \%$ of patients, respectively, were still ill. This pattern suggests that recovery rates tend to be greater in the first few years of followup and thereafter stabilize. An almost three-year follow-up period thus seems to be a reasonable time period to describe the course of the disease in a depressed sample.

Finally, it has been mentioned that "psychiatric research emphasizes case-categorization methods designed to identify putatively discrete episodes of disorder, whereas the psychological approach relies solely on parametric analysis of means and continuously distributed scores" (Shapiro et al., 1995, p. 379). Using stringent definitions of recovery and relapse (Jacobson and Truax, 1991) may have provided more confidence in the results. Using such a method considers values from large samples of clinical and community data to establish norms for functional and dysfunctional ranges. In addition, a multi-level analytical approach was used to confirm the results of the clinical analyses.

\subsection{Implications of the study}

From a clinical perspective, the fact that one-third of the patients never recover from depressive symptoms is alarming. It is recommended that clinical practitioners follow patients who were treated for depression for a significant period of time, as a substantial proportion of them will relapse within the following two years. Follow-up sessions addressing red flags that might precipitate relapse would also be a first option. Clinicians should also consider longer treatment plans for patients with longer histories of depression. Fava et al. (1998)showed that a considerably greater proportion of patients remained symptom-free (approximately 75\%) after two years with a CBT maintenance intervention compared with regular clinical management (less than 20\%). Relapse prevention approaches, such as mindfulnessbased cognitive therapy (Bondolfi et al., 2010; Piet and Hougaard, 2011; Teasdale et al., 2000) and cognitive therapy (e.g., Bockting et al., 2005, 2009), are thus empirically supported continuing treatments for decreasing relapse rates.

The present findings highlight the lack of change in interpersonal problems, which showed lower recovery rates than depressive symptoms. Interpersonal therapy (IPT) has been proven to be efficacious for continuation and maintenance therapy, at least at more than monthly "doses" (Hollon et al., 2002). Patients given continuation IPT showed improved social functioning over time, although this effect did not emerge until 8-10 months of treatment continuation (Frank and Spanier, 1995; Hollon et al., 2002; Weissman et al., 1974). Hence, alternative continuation treatments should be sought for patients with greater interpersonal disabilities.

\section{Role of funding source}

The Portuguese Foundation for Science and Technology (FCT) supported this article through the Research Project "Ambivalence and Unsuccessful Psychotherapy" [PTDC/PSI-PCL/121525/2010], coordinated by M. Gonçalves, and through a doctoral grant to R. Lopes [SFRH/BD/47343/2008].The funders had no role in study design, data collection and analysis, decision to publish, or preparation of the manuscript.

\section{Conflict of interest}

The authors declare they have no conflicts of interest with regard to this paper.

\section{Acknowledgments}

The authors would like to thank the patients who have kindly participated in the study in its several segments; Cátia Von Doellinger for the precious help on the data collection and organization of the follow-up sample; and Michael J. Lambert and William B. Stiles for the encouragementand the valuable input on the data analysis.

\section{References}

American Psychiatric Association, 2000. DSM-IV-TR: Diagnostic and Statistical Manual of Mental Disorders, 4th revised ed.

Anderson, E.M., Lambert, M.J., 2001. A survival analysis of clinically significant change in outpatient psychotherapy. J. Clin. Psychol. 57, 875-888, http://dx.doi. org/10.1002/jclp.1056.

Angst, J., 1992. How recurrent and predictable is depressive illness?. In: Montgomery, F., Rouillon, F. (Eds.), Long-Term Treatment of Depression. Wiley, New York, NY, pp. $1-15$.

Barkham, M., Rees, A., Stiles, W.B., Hardy, G.E., Shapiro, D.A., 2002. Dose-effect relations for psychotherapy of mild depression: a quasi-experimental comparison of effects of 2, 8, and 16 sessions. Psychother. Res. 12, 463-474, http://dx. doi.org/10.1093/ptr/12.4.463.

Barkham, M., Rees, A., Stiles, W.B., Shapiro, D.A., Hardy, G.E., Reynolds, S., 1996. Dose-effect relations in time-limited psychotherapy for depression. J. Consult. Clin. Psychol. 64, 927-935, http://dx.doi.org/10.1037/0022-006X.64.5.927.

Barkham, M., Shapiro, D.A., Hardy, G.E., Rees, A., 1999. Psychotherapy in two-plusone sessions: outcomes of a randomized controlled trial of cognitive-behavioral and psychodynamic-interpersonal therapy for subsyndromal depression. J. Consult. Clin. Psychol. 67, 201-211.

Barkham, M., Stiles, W.B., Shapiro, D.A., 1993. The shape of change in psychotherapy: longitudinal assessment of personal problems. J. Consult. Clin. Psychol. 61, 667-677, http://dx.doi.org/10.1037/0022-006X.61.4.667.

Barkow, K., Maier, W., Üstün, T.B., Gänsicke, M., Wittchen, H.-U., Heun, R., 2003. Risk factors for depression at 12-month follow-up in adult primary health care patients with major depression: an international prospective study. J. Affect. Disord. 76, 157-169, http://dx.doi.org/10.1016/S0165-0327(02)00081-2.

Barnhofer, T., Brennan, K., Crane, C., Duggan, D., Williams, J.M.G., 2014. A comparison of vulnerability factors in patients with persistent and remitting lifetime symptom course of depression. J. Affect. Disord. 152-154, 155-161, http://dx.doi.org/10.1016/j.jad.2013.09.001.

Bauer, S., Lambert, M.J., Nielsen, S.L., 2004. Clinical significance methods: a comparison of statistical techniques. J. Pers. Assess. 82, 60-70, http://dx.doi. org/10.1207/s15327752jpa8201_11.

Beck, A.T., Rush, A.J., Shaw, B.F., Emery, G., 1979. Cognitive Therapy of Depression. Guilford Press, New York.

Beck, A.T., Steer, R.A., Brown, G.K., 1996. Manual for the Beck Depression InventoryII (BDI-II). Psychological Corporation, San Antonio, TX.

Bland, J.M., Altman, D.G., 2000. Statistics notes: the odds ratio. BMJ 320, 1468.

Blay, S.L., Fucks, J.S.V., Barruzi, M., Pietro, M.C.D., Gastal, F.L., Neto, A.M., Souza, M.P. D., Glausiusz, L.R.U., Dewey, M., 2002. Effectiveness of time-limited psychotherapy for minor psychiatric disorders randomised controlled trial evaluating immediate v. long-term effects. Br. J. Psychiatry 180, 416-422, http://dx.doi.org/ 10.1192/bjp.180.5.416.

Bockting, C.L., Schene, A.H., Spinhoven, P., Koeter, M.W., Wouters, L.F., Huyser, J., Kamphuis, J.H., 2005. Preventing relapse/recurrence in recurrent depression with cognitive therapy: a randomized controlled trial. J. Consult. Clin. Psychol. 73, 647-657, http://dx.doi.org/10.1037/0022-006X.73.4.647.

Bockting, C.L., Spinhoven, P., Wouters, L.F., Koeter, M.W., Schene, A.H., 2009. Longterm effects of preventive cognitive therapy in recurrent depression: a 5.5-year follow-up study. J. Clin. Psychiatry 16, 1621, http://dx.doi.org/10.4088/ JCP.08m04784.

Bondolfi, G., Jermann, F., Linden, D., Van, M., Gex-Fabry, M., Bizzini, L., Rouget, B.W. Myers-Arrazola, L., Gonzalez, C., Segal, Z., Aubry, J.-M., Bertschy, G., 2010. Depression relapse prophylaxis with mindfulness-based cognitive therapy: replication and extension in the Swiss health care system. J. Affect. Disord. 122, 224-231, http://dx.doi.org/10.1016/j.jad.2009.07.007.

Brodaty, H., Luscombe, G., Peisah, C., Anstey, K., Andrews, G., 2001. A 25-year longitudinal, comparison study of the outcome of depression. Psychol. Med. 31, 1347-1359, http://dx.doi.org/10.1017/S0033291701004743.

Butler, A.C., Chapman, J.E., Forman, E.M., Beck, A.T., 2006. The empirical status of cognitive-behavioral therapy: a review of meta-analyses. Clin. Psychol. Rev. 26, 17-31, http://dx.doi.org/10.1016/j.cpr.2005.07.003.

Campos, R.C., Gonçalves, B., 2011. The Portuguese version of the beck depression inventory-II (BDI-II). Eur. J. Psychol. Assess. 27, 258-264, http://dx.doi.org/ 10.1027/1015-5759/a000072.

Chambless, D.L., Hollon, S.D., 1998. Defining empirically supported therapies. J. Consult. Clin. Psychol. 66, 7-18, http://dx.doi.org/10.1037/0022-006X.66.1.7.

Coelho, R., Martins, A., Barros, H., 2002. Clinical profiles relating gender and depressive symptoms among adolescents ascertained by the beck depression inventory II. Eur. Psychiatry 17, 222-226, http://dx.doi.org/10.1016/S0924-9338 (02)00663-6.

Cooper, M., 2008. Essential Research Findings in Counselling and Psychotherapy: The Facts are Friendly. SAGE Publications Ltd., London.

Cuijpers, P., van Straten, A., Andersson, G., van Oppen, P., 2008a. Psychotherapy for depression in adults: a meta-analysis of comparative outcome studies. J. Consult. Clin. Psychol. 76, 909-922.

Cuijpers, P., van Straten, A., Warmerdam, L., Andersson, G., 2008b. Psychological treatment of depression: a meta-analytic database of randomized studies. BMC Psychiatry 8, 36, http://dx.doi.org/10.1186/1471-244X-8-36.

De Jong, K., Nugter, M.A., Polak, M.G., Wagenborg, J.E.A., Spinhoven, P., Heiser, W.J., 2007. The outcome questionnaire (OQ-45) in a Dutch population: a cross-cultural validation. Clin. Psychol. Psychother. 14, 288-301, http://dx.doi.org/10.1002/cpp.529.

Deffenbacher, J.L., Oetting, E.R., Huff, M.E., Thwaites, G.A., 1995. Fifteen-month follow-up of social skills and cognitive-relaxation approaches to general anger 
reduction. J. Couns. Psychol. 42, 400-405, http://dx.doi.org/10.1037/00220167.42.3.400.

Demaat, S., Dekker, J., Schoevers, R., Dejonghe, F., 2007. Relative efficacy of psychotherapy and combined therapy in the treatment of depression: a meta-analysis. Eur. Psychiatry 22, 1-8, http://dx.doi.org/10.1016/j.eurpsy. 2006.10.008.

DeRubeis, R.J., Hollon, S.D., Amsterdam, J.D., Shelton, R.C., Young, P.R., Salomon, R. M., O'Reardon, J.P., Lovett, M.L., Gladis, M.M., Brown, L.L., Gallop, R., 2005. Cognitive therapy vs. medications in the treatment of moderate to severe depression. Arch. Gen. Psychiatry 62, 409.

Dobson, K.S., 1989. A meta-analysis of the efficacy of cognitive therapy for depression. J. Consult. Clin. Psychol. 57, 414-419.

Elkin, I., Shea, M.T., Watkins, J.T., Imber, S.D., Sotsky, S.M., Collins, J.F., Glass, D.R. Pilkonis, P.A., Leber, W.R., Docherty, J.P., Fiester, S.J., Parloff, M.B., 1989. National institute of mental health treatment of depression collaborative research program: general effectiveness of treatments. Arch. Gen. Psychiatry 46, 971-982, http://dx.doi.org/10.1001/archpsyc.1989.01810110013002.

Ellison, J.A., Greenberg, L.S., Goldman, R.N., Angus, L., 2009. Maintenance of gains following experiential therapies for depression. J. Consult. Clin. Psychol. 77, 103-112, http://dx.doi.org/10.1037/a0014653.

Fava, G.A., Rafanelli, C., Grandi, S., Conti, S., Belluardo, P., 1998. Prevention of recurrent depression with cognitive behavioral therapy: preliminary findings. Arch. Gen. Psychiatry 55, 816-820, http://dx.doi.org/10.1001/archpsyc.55.9.816.

Frank, E., Spanier, C., 1995. Interpersonal psychotherapy for depression: overview, clinical efficacy, and future directions. Clin. Psychol. Sci. Pract. 2, 349-369, http: //dx.doi.org/10.1111/j.1468-2850.1995.tb00048.x.

Gibbons, C.J., Fournier, J.C., Stirman, S.W., DeRubeis, R.J., Crits-Christoph, P., Beck, A. T., 2010. The clinical effectiveness of cognitive therapy for depression in an outpatient clinic. J. Affect. Disord. 125, 169-176, http://dx.doi.org/10.1016/j. jad.2009.12.030.

Gloaguen, V., Cottraux, J., Cucherat, M., Blackburn, I.M., 1998. A meta-analysis of the effects of cognitive therapy in depressed patients. J. Affect. Disord. 49, 59-72.

Gonçalves, M.M., Bento, T., 2008. Manual Terapêutico Psicoterapia Narrativa de ReAutoria.

Gonçalves, M.M., Bento, T., Lopes, R.T., Salgado, J., 2009. Manual da Escala de Adesão e Competência.

Hammen, C., Brennan, P.A., 2002. Interpersonal dysfunction in depressed women: impairments independent of depressive symptoms. J. Affect. Disord. 72 , 145-156, http://dx.doi.org/10.1016/S0165-0327(01)00455-4.

Hansen, N.B., Lambert, M.J., Forman, E.M., 2002. The psychotherapy dose-response effect and its implications for treatment delivery services. Clin. Psychol. Sci. Pract. 9, 329-343, http://dx.doi.org/10.1093/clipsy.9.3.329.

Hatfield, D.R., Ogles, B.M., 2004. The use of outcome measures by psychologists in clinical practice. Prof. Psychol. Res. Pract. 35, 485-491, http://dx.doi.org/ 10.1037/0735-7028.35.5.485

Hecht, H., Genzwürker, S., Helle, M., van Calker, D., 2005. Social functioning and personality of subjects at familial risk for affective disorder. J. Affect. Disord. 84, 33-42, http://dx.doi.org/10.1016/j.jad.2004.09.002.

Hilsenroth, M.J., Ackerman, S.J., Blagys, M.D., 2001. Evaluating the phase model of change during short-term psychodynamic psychotherapy. Psychother. Res. 11, 29-47, http://dx.doi.org/10.1080/713663851.

Hollon, S.D., DeRubeis, R.J., Shelton, R.C., Amsterdam, J.D., Salomon, R.M., O’Reardon, J.P., Lovett, M.L., Young, P.R., Haman, K.L., Freeman, B.B., Gallop, R., 2005. Prevention of relapse following cognitive therapy vs medications in moderate to severe depression. Arch. Gen. Psychiatry 62, 417-422, http://dx.doi.org/ 10.1001/archpsyc.62.4.417.

Hollon, S.D., Ponniah, K., 2010. A review of empirically supported psychological therapies for mood disorders in adults. Depress. Anxiety 27, 891-932, http://dx. doi.org/10.1002/da.20741.

Hollon, S.D., Thase, M.E., Markowitz, J.C., 2002. Treatment and prevention of depression. Psychol. Sci. Public Interest 3, 39.

Horowitz, L.M., Alden, L.E., Wiggins, J.S., Pincus, A.L., 2000. IIP, Inventory of Interpersonal Problems Manual. Psychological Corporation, New York, NY.

Horowitz, L.M., Rosenberg, S.E., Baer, B.A., Ureño, G., Villaseñor, V.S., 1988. Inventory of interpersonal problems: psychometric properties and clinical applications. J. Consult. Clin. Psychol. 56, 885-892, http://dx.doi.org/10.1037/ 0022-006X.56.6.885.

Howard, K.I., Lueger, R.J., Maling, M.S., Martinovich, Z., 1993. A phase model of psychotherapy outcome: causal mediation of change. J. Consult. Clin. Psychol. 61, 678-685, http://dx.doi.org/10.1037/0022-006X.61.4.678.

Jacobson, N.S., Truax, P., 1991. Clinical significance: a statistical approach to defining meaningful change in psychotherapy research. J. Consult. Clin. Psychol. 59, 12-19.

Judd, L.L., Akiskal, H.S., Maser, J.D., Zeller, P.J., Endicott, J., Coryell, W., Paulus, M.P., Kunovac, J.L., Leon, A.C., Mueller, T.I., Rice, J.A., Keller, M.B., 1998. A prospective 12 -year study of subsyndromal and syndromal depressive symptoms in unipolar major depressive disorders. Arch. Gen. Psychiatry 55, 694-700, http: //dx.doi.org/10.1001/archpsyc.55.8.694.

Katz, M.M., Klerman, G.L., 1979. Introduction: overview of the clinical studies program. Am. J. Psychiatry 136, 49-51.

Keller, M.B., Boland, R.J., 1998. Implications of failing to achieve successful longterm maintenance treatment of recurrent unipolar major depression. Biol. Psychiatry 44, 348-360, http://dx.doi.org/10.1016/S0006-3223(98)00110-3.

Keller, M.B., Lavori, P.W., Mueller, T.I., Endicott, J., Coryell, W., Hirschfeld, R., Shea, T., 1992. Time to recovery, chronicity, and levels of psychopathology in major depression: a 5-year prospective follow-up of 431 subjects. Arch. Gen. Psychiatry $49,809-816$.
Keller, M.B., Shapiro, R.W., 1982. "Double depression”: superimposition of acute depressive episodes on chronic depressive disorders. Am. J. Psychiatry 139, 438-442.

Keller, M.B., Shapiro, R.W., Lavori, P.W., Wolfe, N., 1982. Recovery in major depressive disorder: analysis with the life table and regression models. Arch. Gen. Psychiatry 39, 905.

Kendall, P.C., Holmbeck, G., Verduin, T., 2004. Methodology, design, and evaluation in psychotherapy research. In: Lambert, M.J. (Ed.), Bergin and Garfield's Handbook of Psychotherapy and Behavior Change. Wiley, New York, pp. 16-43.

Kopta, S.M., Howard, K.I., Lowry, J.L., Beutler, L.E., 1994. Patterns of symptomatic recovery in psychotherapy. J. Consult. Clin. Psychol. 62, 1009-1016.

Lambert, M.J., 2007. Presidential address: What we have learned from a decade of research aimed at improving psychotherapy outcome in routine care. Psychother. Res. 17, 1-14, http://dx.doi.org/10.1080/10503300601032506.

Lambert, M.J., Burlingame, G.M., Umphress, V., Hansen, N.B., Vermeersch, D.A. Clouse, G.C., Yanchar, S.C., 1996a. The reliability and validity of the outcome questionnaire. Clin. Psychol. Psychother. 3, 249-258.

Lambert, M.J., Hansen, N.B., Umphress, V., Lunnen, K., Okiishi, J., Burlingame, G.M., Reisenger, C.W., 1996b. Administration and scoring manual for the Outcome Questionnaire (OQ 45.2). American Professional Credentialing Services LLC, Stevenson, MD.

Lambert, M.J., Ogles, B.M., 2004. The efficacy and effectiveness of psychotherapy. In: Lambert, M.J. (Ed.), Bergin and Garfield's Handbook of Psychotherapy and Behavior Change. Wiley, New York, pp. 139-193.

Leahy, R.L., Holland, S.J., 2000. Treatment Plans and Interventions for Depression and Anxiety Disorders. The Guilford Press, New York, NY.

Lopes, R.T., Gonçalves, M.M., Fassnacht, D.B., Machado, P.P.P., Sousa, I., 2013. Time to improve and recover from depressive symptoms and interpersonal problems in a clinical trial. Clin. Psychol. Psychother. , http://dx.doi.org/10.1002/cpp.1873.

Lopes, R.T., Gonçalves, M.M., Machado, P.P.P., Sinai, D., Bento, T., Salgado, J., 2014 Narrative therapy vs. cognitive-behavioral therapy for moderate depression: empirical evidence from a controlled clinical trial. Psychother. Res. 0, 1-13, http://dx.doi.org/10.1080/10503307.2013.874052.

Machado, P.P.P., Fassnacht, D., 2014. Normative Data, Reliability and Clinical Significance Cut-offs for the Portuguese Version of the Outcome Questionnaire (OQ-45).

McEvoy, P.M., Burgess, M.M., Nathan, P., 2013. The relationship between interpersonal problems, negative cognitions, and outcomes from cognitive behavioral group therapy for depression. J. Affect. Disord. 150, 266-275, http://dx doi.org/10.1016/j.jad.2013.04.005.

Minami, T., Wampold, B.E., Serlin, R.C., Kircher, J.C., Brown, G.S., 2007. Benchmarks for psychotherapy efficacy in adult major depression. J. Consult. Clin. Psychol. 75, 232-243, http://dx.doi.org/10.1037/0022-006X.75.2.232.

Mueller, T.I., Keller, M.B., Leon, A.C., Solomon, D.A., Shea, M.T., Coryell, W., Endicott, J., 1996. Recovery after 5 years of unremitting major depressive disorder. Arch. Gen. Psychiatry 53, 794, http://dx.doi.org/10.1001/archpsyc.1996.018300900 40006.

Nicholson, R.A., Berman, J.S., 1983. Is follow-up necessary in evaluating psychotherapy? Psychol. Bull. 93, 261-278.

Ogles, B.M., Lunnen, K.M., Bonesteel, K., 2001. Clinical significance: history, application, and current practice. Clin. Psychol. Rev. 21, 421-446, http://dx. doi.org/10.1016/S0272-7358(99)00058-6.

Piet, J., Hougaard, E., 2011. The effect of mindfulness-based cognitive therapy for prevention of relapse in recurrent major depressive disorder: A systematic review and meta-analysis. Clin. Psychol. Rev. 31, 1032-1040, http://dx.doi.org/ 10.1016/j.cpr.2011.05.002.

Preacher, K.J., Briggs, N.E., 2001. Interactive Fisher's Exact Test [WWW Document]. Calc. Fish. Exact Test Interact. Calc. Tool Fish. Exact Probab. Test $2 \times 2$ Tables Comput. Softw. URL 〈http://www.quantpsy.org/fisher/fisher.htm〉 (accessed 24.7.12).

Robinson, L.A., Berman, J.S., Neimeyer, R.A., 1990. Psychotherapy for the treatment of depression: a comprehensive review of controlled outcome research. Psychol. Bull. 108, 30-49, http://dx.doi.org/10.1037/0033-2909.108.1.30.

Rush, A.J., Beck, A.T., Kovacs, M., Hollon, S.D., 1977. Comparative efficacy of cognitive therapy and pharmacotherapy in the treatment of depressed outpatients. Cogn. Ther. Res. 1, 17-37, http://dx.doi.org/10.1007/BF01173502.

Seggar, L.B., Lambert, M.J., Hansen, N.B., 2002. Assessing clinical significance: application to the beck depression inventory. Behav. Ther. 33, 253-269.

Shapiro, D.A., Rees, A., Barkham, M., Hardy, G., Reynolds, S., Startup, M., 1995. Effects of treatment duration and severity of depression on the maintenance of gains after cognitive-behavioral and psychodynamic-interpersonal psychotherapy. J. Consult. Clin. Psychol. 63, 378-387, http://dx.doi.org/10.1037/0022-006X.63.3.378.

Shea, M.T., Elkin, I., Imber, S.D., Sotsky, S.M., Watkins, J.T., Collins, J.F., Pilkonis, P.A., Beckham, E., Glass, D.R., Dolan, R.T., Parloff, M.B., 1992. Course of depressive symptoms over follow-up: findings from the national institute of mental health treatment of depression collaborative research program. Arch. Gen. Psychiatry 49, 782-787, http://dx.doi.org/10.1001/archpsyc.1992.01820100026006.

Snell, M.N., Mallinckrodt, B., Hill, R.D., Lambert, M.J., 2001. Predicting counseling center clients' response to counseling: a 1-year follow-up. J. Couns. Psychol. 48 463-473, http://dx.doi.org/10.1037/0022-0167.48.4.463.

Steer, R.A., Brown, G.K., Beck, A.T., Sanderson, W.C., 2001. Mean beck depression inventory-II scores by severity of major depressive episode. Psychol. Rep. 88, 1075-1076.

Swift, J.K., Callahan, J.L., Heath, C.J., Herbert, G.L., Levine, J.C., 2010. Applications of the psychotherapy phase model to clinically significant deterioration. Psychother. Theory Res. Pract. Train. 47, 235-248, http://dx.doi.org/10.1037/ a0019787. 
Teasdale, J.D., Segal, Z.V., Mark, J., Ridgeway, V.A., Soulsby, J.M., Lau, M.A., 2000 Prevention of relapse/recurrence in major depression by mindfulness-based cognitive therapy. J. Consult. Clin. Psychol. 68, 615-623, http://dx.doi.org/ 10.1037/0022-006X.68.4.615.

Umphress, V.J., Lambert, M.J., Smart, D.W., Barlow, S.H., Clouse, G., 1997. Concurrent and construct validity of the outcome questionnaire. J. Psychoeduc. Assess. 15, 40-55, http://dx.doi.org/10.1177/073428299701500104.

Vromans, L.P., Schweitzer, R.D., 2011. Narrative therapy for adults with major depressive disorder: Improved symptom and interpersonal outcomes. Psychother. Res. 21, 4-15, http://dx.doi.org/10.1080/10503301003591792.
Weissman, M.M., Klerman, G., Paykel, E., Prusoff, B., Hanson, B., 1974. Treatment effects on the social adjustment of depressed patients. Arch. Gen. Psychiatry 30, 771-778, http://dx.doi.org/10.1001/archpsyc.1974.01760120033006.

Westen, D., Morrison, K., 2001. A multidimensional meta-analysis of treatments for depression, panic, and generalized anxiety disorder: an empirical examination of the status of empirically supported therapies. J. Consult. Clin. Psychol. 69, 875-899, http://dx.doi.org/10.1037/0022-006X.69.6.875.

White, M., 2007. Maps of Narrative Practice. WW Norton \& Company, New York, NY. White, M., Epston, D., 1990. Narrative Means to Therapeutic Ends. WW Norton \& Company, New York, NY. 